\title{
Trust Model for Online Reviews of Tourism Services and Evaluation of Destinations
}

\author{
Josef Zelenka *(D), Tracy Azubuike and Martina Pásková (i)
}

check for

updates

Citation: Zelenka, Josef, Tracy Azubuike, and Martina Pásková. 2021. Trust Model for Online Reviews of Tourism Services and Evaluation of Destinations. Administrative Sciences 11: 34. https://doi.org/10.3390/ admsci11020034

Received: 31 January 2021

Accepted: 19 March 2021

Published: 24 March 2021

Publisher's Note: MDPI stays neutral with regard to jurisdictional claims in published maps and institutional affiliations.

Copyright: (C) 2021 by the authors. Licensee MDPI, Basel, Switzerland. This article is an open access article distributed under the terms and conditions of the Creative Commons Attribution (CC BY) license (https:/ / creativecommons.org/licenses/by/ $4.0 /)$.
Faculty of Informatics and Management, University of Hradec Králové, 50003 Hradec Králové, Czech Republic tracy.azubuike@uhk.cz (T.A.); martina.paskova@uhk.cz (M.P.)

* Correspondence: josef.zelenka@uhk.cz; Tel.: +420-49333-2337

\begin{abstract}
Obtaining information about destinations and services they provide is ever more based on user-generated content (UGC), which includes reviews of tourism services as well as evaluation of attractions and destinations by visitors. The growing importance of reviews of tourism services is recognized by tourism service providers, and some of them influence the content of reviews on review sites. At the same time, procedures for the prevention of false and misleading reviews, as well as their detection, are being intensively developed. This is documented in relevant sources, which were identified especially on the Web of Science, Scopus, Sciencedirect, Researchgate and the websites of MDPI, Emerald and Taylor \& Francis Online. The aim of this study is to reveal how the verification of reviews can be improved with the intention to increase confidence in the review sites. In the form of case studies of TripAdvisor and Booking.com, the current rise of trust in reviews on these review sites was analysed and documented. The outputs of research include a SWOT analysis, processual analysis and an analysis of verification process, conditions, factors affecting trust in reviews on review sites. On these bases, a conceptual model for providing verified reviews of tourism services or verified destination assessment and two process models for providing verified reviews of tourism services and for providing verified destination assessment have been drawn up.
\end{abstract}

Keywords: trust model; review site; fake review; e-WOM; consumer-generated content (CGC); user-generated content (UGC)

\section{Introduction}

As research conducted in various years shows (e.g., TIA 2005; Leung et al. 2013; Trend 2013; Prabu 2014; Dwityas and Briandana 2017; Tham et al. 2020), the share of people who use search engines, social media and specifically review websites when planning their vacation is constantly increasing. As for the use of search engines for planning their trips, the American Tourism Association reported a share of $64 \%$ of passengers in 2004 (TIA 2005) and, according to Google, in 2013 it was already more than $80 \%$ of people (Trend 2013). Concerning review sites, the PhoCusWright survey showed (Prabu 2014) that as early as 2013 , more than $80 \%$ of passengers in the UK read between six and twelve reviews before deciding which hotel to stay in, and 53\% stated that they would not be willing to book a hotel for which no reviews have been written.

An analysis of review sites shows that the first review sites for movies, sports, and businesses (rateitall.com, deja.com, Epinions) appeared on the Internet in 1999. Reviews for tourism followed soon (2000). TripAdvisor and Booking.com (both operating since 2000) have been playing arguably the most important role among review sites in tourism for several years. This is evidenced by published statistics and various studies of their use by users. TripAdvisor content is primarily devoted to user reviews and photos of places and facilities related to tourism (e.g., hotels, restaurants, museums, theatres, galleries, monuments, and natural attractions). According to TripAdvisor (2020a), their platform helps nearly half a billion travellers each month; it is also the largest travel platform in the 
world and it is available in 49 markets and in 28 languages. TripAdvisor is available on the web, as well as mobile apps for Android and iOS. In 2014, according to Okazaki et al. (2017), 100 million people downloaded TripAdvisor, with a total of 200 million users (Statista 2020). In 2019, TripAdvisor already boasted 859 million users (Statista 2020). Booking.com specializes in booking accommodation; their website is available in 43 languages and offers more than 28 million registered accommodation units (Booking.com 2020a, 2020b).

The role of review sites must be perceived in connection with the importance of electronic WOM (eWOM) for tourism participants. According to Nam et al. (2020b), the influence of eWOM is undeniable, with $91 \%$ of individuals viewing blogs, product reviews or other online comments created by users before purchasing a product or service, $84 \%$ of respondents say they trust online reviews as much as personal recommendations, and $74 \%$ of consumers say they trust companies more if they have positive reviews. For instance, in 2012, according to a Travel Daily News survey (Travel Daily News 2012), 87\% of respondents thought that reviews on TripAdvisor had helped them choose a hotel with more confidence, and $98 \%$ thought that the reviews on the site were accurate. Most authors report a positive effect of positive reviews on the demand for tourism services (e.g., Mauri and Minazzi 2013). On the other hand, some authors report a neutral effect (El-Said 2020). The significant impact of negative reviews on consumer decisions, causing the outflow of customers from the affected tourism service provider, has long been confirmed (Lee et al. 2008; Sparks and Browning 2011; Mauri and Minazzi 2013; El-Said 2020). The impact of reviews on consumers is also enhanced by the geographical proximity of the reviewer and the consumer (Chan et al. 2017). As reported by Casaló et al. (2015), putting an accommodation facility on the list of best/worst hotels has a positive/negative impact on customer decisions, especially if the list is published in a well-known review site (e.g., TripAdvisor, Booking.com, Expedia, Yelp).

Review sites are important, not only for decision-making by potential users of tourism services and visitors to destinations (e.g., Zervas et al. 2021), but also as sources of valuable information about the way of thinking and satisfaction or dissatisfaction of tourism participants. Review sites are significant for the implementation of marketing of tourism services, attractions and destinations. They are also an important factor in satisfaction with tourism services and expectation created by destinations and are considered a part of the total tourism product. For all these reasons, the level of veracity of reviews contained in review sites has become an important research topic. As a result, various methods for detecting false reviews are discussed and developed, and various complex procedures for verifying reviews and reviewers are becoming a common practice of review sites. This dynamic development of the significance of review sites, various ways of deliberate influencing reviews (e.g., by hotel managers), the creation of intentionally false reviews and their detection led the authors to formulate the basic objective of their article. The aim of this study is to overcome the identified weaknesses in the review verification process by drawing up conceptual and process models. Their implementation should increase confidence in tourism review sites.

\section{Theoretical Background}

\subsection{Social Media and User-Generated Content}

Social media are important for information retrieval in tourism (Xiang and Gretzel 2010; Zeng and Gerritsen 2014) and as a platform for creating user-generated events (UGEs; Marine-Roig et al. 2017). Certain considerations are relevant in analysing the use of social media. Firstly, it is appropriate to respect their different uses by different segments of tourism participants (e.g., Amaro et al. 2016). Secondly, it is necessary to respond adequately to the challenges that social media create for marketing (Hofacker and Belanche 2016). The use of social media in preparation for and during the journey also has the potential to reduce tourism cognitive distances, as described in detail by Ankomah and Crompton (1992). The content of social media, including review sites, is in the case of tourism created by providers and intermediaries of tourism services and destination 
management organizations (collectively referred to as firm-generated content-FGC) and users (user-generated content-UGC). UGC can be divided into primary user-generated content (photos, videos, stories, reviews, etc.) and secondary user-generated content (comments on the primary UGC and the primary FGC, including comments to reviews, likes, recommendations for tracking content, link forwarding, etc.). Some of the FGC content directly relates to the UGC, in particular comments and responses to user reviews and false "corporate" reviews that look like UGC.

A frequent topic of research is the degree and nature of UGC's credibility on social media, while the undesirable use and content of social media relates to non-personal communication and anonymity of part of the content (Mkono 2018). Some researchers aim to understand reasons for writing false reviews and other false UGC messages on social media (Choi et al. 2017). At present, as evidenced by various studies (e.g., Berhanu and Raj 2020), confidence in the veracity of the UGC on social media persists. Nonetheless, according to Berhanu and Raj (2020), this confidence decreases with the increasing age of respondents. This trust is influenced by a number of factors (e.g., level and manner of communication, transparency, interconnectedness), as shown by, among others, Li and Suh (2015), Rajamma et al. (2019), Grewal and Stephen (2019) and Lee and Hong (2019). Other studies (e.g., Munar and Jacobsen 2013) found that a lower level of trust in UGC on social media depends on the type of social media.

Research and review articles have repeatedly confirmed (e.g., Dickinger 2011; Fotis et al. 2012; Goh et al. 2013; Filieri et al. 2015; Maria-Irina and Istudor 2019; Verma and Yadav 2021) that UGC is usually perceived as more credible compared to FGC, including social media of tourist destinations, service providers, and tourism services intermediaries. At the beginning of UGC development, some studies showed opposite results, emphasizing the higher credibility of FGC (e.g., Cox et al. 2009). Other studies described the relationship between UGC and FGC on multiple levels (e.g., Colicev et al. 2018) and highlighted the significant influence of FGC on tourism participants' decision-making. These differing results can be explained by the fact that for UGC, it is not only the similarity to the immediacy of personal oral communication (WOM), but also the perceived level of users' trust in UGC, that are important (Munar and Jacobsen 2013; Owusu et al. 2016). As various factors influence this trust, the research also focuses on the factors that influence the level of trust in UGC in connection with its use as a resource for booking tourism services (e.g., Rajamma et al. 2019). However, the level and conditions of UGC's credibility, in connection with the occurrence of intentionally distorted and fraudulent evaluations of tourism services, attractions and destinations, have also been discussed for a long time (Burgess et al. 2009, 2011; Reyes-Menendez et al. 2019a; Fedeli 2020). Trust in the truthfulness, accuracy and sincerity of UGC content is a prerequisite for using UGC in information retrieval, vacation planning (Enter and Michopoulou 2013; Mendes-Filho et al. 2018) and comparing destinations and quality of tourism service providers and intermediaries. There is a new "category" of social media content, namely that created or shared and commented on by social media influencers (e.g., YouTubers, bloggers), whose credibility and influence on the preferences and behaviour of potential tourism participants are also frequently examined (Bokunewicz and Shulman 2017; Gretzel 2018; Lou and Yuan 2019; Jaya and Prianthara 2020). Similar attention is paid to trusted reviewers (Shankadeep et al. 2017) and their impact on increasing trust in tourism services (Sharma and Aggarwal 2020). The research also looks into the influence of the nature of the resource on its credibility and level of use (e.g., Burgess et al. 2011; Casaló et al. 2015). The results of these studies (Burgess et al. 2011; Casaló et al. 2015) show that online reviews are perceived by users as more useful and credible when published by well-known online travel communities (e.g., Lonely Planet, TripAdvisor).

\section{2. $e W O M$}

Research conducted from the emergence of social media to the present day agrees that there is in tourism growing interest in e-WOM (e.g., Litvin et al. 2008; Trusov et al. 2008; 
Jalilvand et al. 2011; Sotiriadis and Zyl 2013; Wang 2015; Baka 2016; Nam et al. 2020a, 2020b; $\mathrm{Bu}$ et al. 2020). It is particularly true of UGC that has an impact on changing the preferences of potential tourism participants, their actions and the way, quality and quantity of tourism services or choice of tourist attractions, choice of destination and length of stay in it. At the same time, the traditional higher influence of oral WOM in comparison with e-WOM persists (e.g., Hernández-Méndez et al. 2015; Ishida et al. 2016). However, the result of Duffy (2015) is interesting - while WOM is usually more reliable than e-WOM, in case detailed information needs to be obtained (e.g., a specific hotel), e-WOM can be considered a more valuable source of information.

Social media and especially e-WOM are important for the marketing of tourism services (Hudson and Thal 2013; Zeng and Gerritsen 2014; Tsao et al. 2015; Baka 2016; Pantano et al. 2017; Giglio et al. 2019; Reyes-Menendez et al. 2019b; Zervas et al. 2021). The analysis of their content can be used to increase the quality of marketing of tourism services, tourist attractions or destinations (Lai 2011; Lai and To 2015). It is also possible to implement strategic social media marketing (Felix et al. 2017). Many studies document the importance of social media for destination marketing (Lange-Faria and Elliot 2012; Alizadeh and Isa 2014, 2015; Mukherjee and Nagabhushana 2016; Rahman 2017; Bokunewicz and Shulman 2017), including the role of e-WOM (Tham et al. 2013; Abubakar 2016; Ishida et al. 2016; Cheng et al. 2020).

\subsection{Influence of Online Reviews on Customer Decisions}

Many studies (e.g., Ham et al. 2019) confirm the significant influence of online reviews of service quality, attractions and destinations on the decision-making process of potential tourism participants. Applications are created that extract useful information from reviews, such as the evaluation of attractions on TripAdvisor (Guy et al. 2017) and multi-criteria evaluation of the quality and cost-effectiveness of hotel services (Huang et al. 2018). On the contrary, some studies (Ert et al. 2016) question the influence of reviews in relation to other factors and demonstrate the decisive influence of photographs on customer decisions, as in the case of Airbnb. The impact of reviews on customers is sometimes viewed as much more complex. For instance, Ahmad and Sun (2018) analysed factors involved in assessing the veracity of reviews (false identity and ulterior motivations) and the influence of critical review on more frequent consumer involvement in writing critical reviews in case of poor-quality service.

\subsection{Trust in UGC-Based Review Sites}

The use and importance of review sites based on UGC (as well as that of content created intentionally by tour operators) and high user trust in the veracity of their content have been growing (e.g., López and Taño 2017; Harris 2018). According to Filieri et al. (2015), however, maintaining a high level of trust in UGC is an increasingly challenging task for review site managers. For instance, TripAdvisor was forced by the British Advertising Standards Authority to remove its "misleading" slogans referring to the credible and honest nature of all reviews hosted on its website. Methods for improving the quality of knowledge gained from review sites are also being developed, with collective analysis of reviews and their aggregation being a typical approach (e.g., Dai et al. 2012; Leal et al. 2018, 2019; Nilashi et al. 2018). According to Fogel and Murphy (2018), experience with using online reviews on TripAdvisor has increased their later use and positively influenced the willingness to purchase reviewed services, which reflects growing confidence in TripAdvisor reviews. Nevertheless, Duffy (2017) emphasizes the dominant role of self-confidence compared to trust in TripAdvisor and reviewers.

Models are also being developed (Baka 2016) on how to strategically use UGC in marketing, specifically reviews on review sites to increase one's own reputation, and appropriate research directions are proposed (Lu and Stepchenkova 2015; Wu et al. 2020). The greatest attention is paid to reviews of hotel services (e.g., Schuckert et al. 2015; Akhtar et al. 2019; An et al. 2020). The degree to which destination reviews by amateurs and 
professionals influence the behaviour of tourism participants is also compared. According to research by Vincent (2018), professional reviews influence tourism participants to a greater extent.

In recent years, however, the reliability of review sites, especially the most popular ones (e.g., TripAdvisor, Booking.com), has been extensively discussed in the mass media (Streitfield 2011; Tuttle 2012; Smith 2013; Lipson 2016; Beaton 2018). It has also been analysed in professional articles (Jindal and Liu 2008; Jeacle and Carter 2011; Filieri et al. 2015; Wu et al. 2020; Nam et al. 2020a, 2020b; Mahat and Hanafiah 2020). At the same time, new knowledge is being gained about the motivations and reasons for the systematic review content manipulation by tourism service providers (e.g., Gossling et al. 2018), including ways of influencing the positivity of reviews (Magno et al. 2018). The percentage of false reviews is estimated at around 20\% (Schuckert et al. 2016).

Various types of data analysis of review sites (e.g., data mining, expert systems), experiments and studies of hotel managers' practices (e.g., Gossling et al. 2018; Gössling et al. 2019) regularly document that not all consumer reviews are written by real customers with the motivation to share experience with other customers and possibly advise them. Part of the review site content about hotel services is thus misleading (Jindal and Liu 2008; Filieri et al. 2015; Akhtar et al. 2019). Managers' responses to reviews may be perceived differently by users and may even reduce the credibility of reviews, as shown in the case of TripAdvisor by Xu et al. (2020). Reyes-Menendez et al. (2019a) used the PRISMA methodology to provide a systematic review of articles published in the Web of Science on the issue of false reviews.

\subsection{Methods for Detecting False Reviews}

In recent years, in connection with the growing attention paid to fake online reviews (e.g., Song et al. 2017; Wu et al. 2020; Li et al. 2020), great efforts have been made to develop methods for detecting false messages. This effort is also evidenced by the growing number of articles (e.g., Cardoso et al. 2018; Cai and Zhu 2020; Wu et al. 2020). There is also the effort to understand the significance of psychological cues, time distance, and reviewer location for writing false reviews ( $\mathrm{Li}$ et al. 2020), which would increase the effectiveness of methods for searching for such reviews. Finding false reviews and eliminating them not only help maintain the trust of potential customers in review sites, but also further develop methods of mass analysis of these reviews, used as an important basis for marketing and management decisions (e.g., Bi et al. 2019; Kauffmann et al. 2020; Chang et al. 2020).

Due to the number of online reviews, it is necessary to develop and use automatic tools using machine learning approaches (Martinez-Torres and Toral 2019). According to Cardoso et al. (2018), Barbado et al. (2019), Wu et al. (2020) and Zheng et al. (2021), methods for detecting false reviews are principally based on content-based spam filtering, and behaviour-based spam filtering (Buccafurri et al. 2015; Zhang et al. 2016; Kumar et al. 2019). Furthermore, they are based on the analysis of the reviewer's profile and their relationships on social media (Kumar et al. 2018, 2019; Song et al. 2017), spammer groups detection, demographic bias of reviewers and spam detection based on information about the product.

Various methods are used to implement these basic detection procedures. They are based on mathematical methods, analysis of traffic and relationships in computer networks (including analysis of usage history), modelling, artificial intelligence, and last but not least, expert evaluation by humans. Methods, both new and traditional, are used to detect false and intentionally distorted messages, include in particular (for a review, see Song et al. 2017; Wu et al. 2020):

- $\quad$ statistical methods (Hu et al. 2012; Song et al. 2017; Harris 2018; Kumar et al. 2019),

- text analysis (Harris 2018; Barbado et al. 2019; Kauffmann et al. 2020), which in recent years includes sentiment/emotional analysis and its relationship to overall evaluation (Harris 2018; Martinez-Torres and Toral 2019; Valdivia et al. 2019; Gadek and Guélorget 2020; Moon et al. 2020), 
- evaluating the behaviour of reviewers and, where appropriate, modelling their behaviour (Buccafurri et al. 2018; Kumar et al. 2019),

- establishing rules for trust networks and detecting breaches of these rules (Buccafurri et al. 2015),

- neural networks (Jiang et al. 2020),

- human control; however, as shown by, for example, Plotkina et al. (2020), the reliability of human evaluation is only about $57 \%$ compared to text analysis tools with a detection reliability of $81 \%$; higher accuracy of machine evaluation is also confirmed by Buccafurri et al. (2018).

\subsection{Factors and Contexts of Achieving Trust in Reviews on Review Sites}

As summarized in Figure 1, the results of the secondary research of factors and contexts of the achieving credibility can be divided into its objectives (Filieri et al. 2015; Barbado et al. 2019; Wu et al. 2020; Zheng et al. 2021), ways to ensure it (Cardoso et al. 2018; Barbado et al. 2019; Wu et al. 2020; TripAdvisor 2020a; Zheng et al. 2021), problems involved (Barbado et al. 2019; Zheng et al. 2021), and who it concerns (TripAdvisor 2020a). The described objectives represent the knowledge base for defining the conditions of the proposed trust model for online reviews of tourism services and evaluation of destinations. This proposed model of trust also respects all the problems described in Figure 1, focusing in particular on the existence of fraudulent reviews.

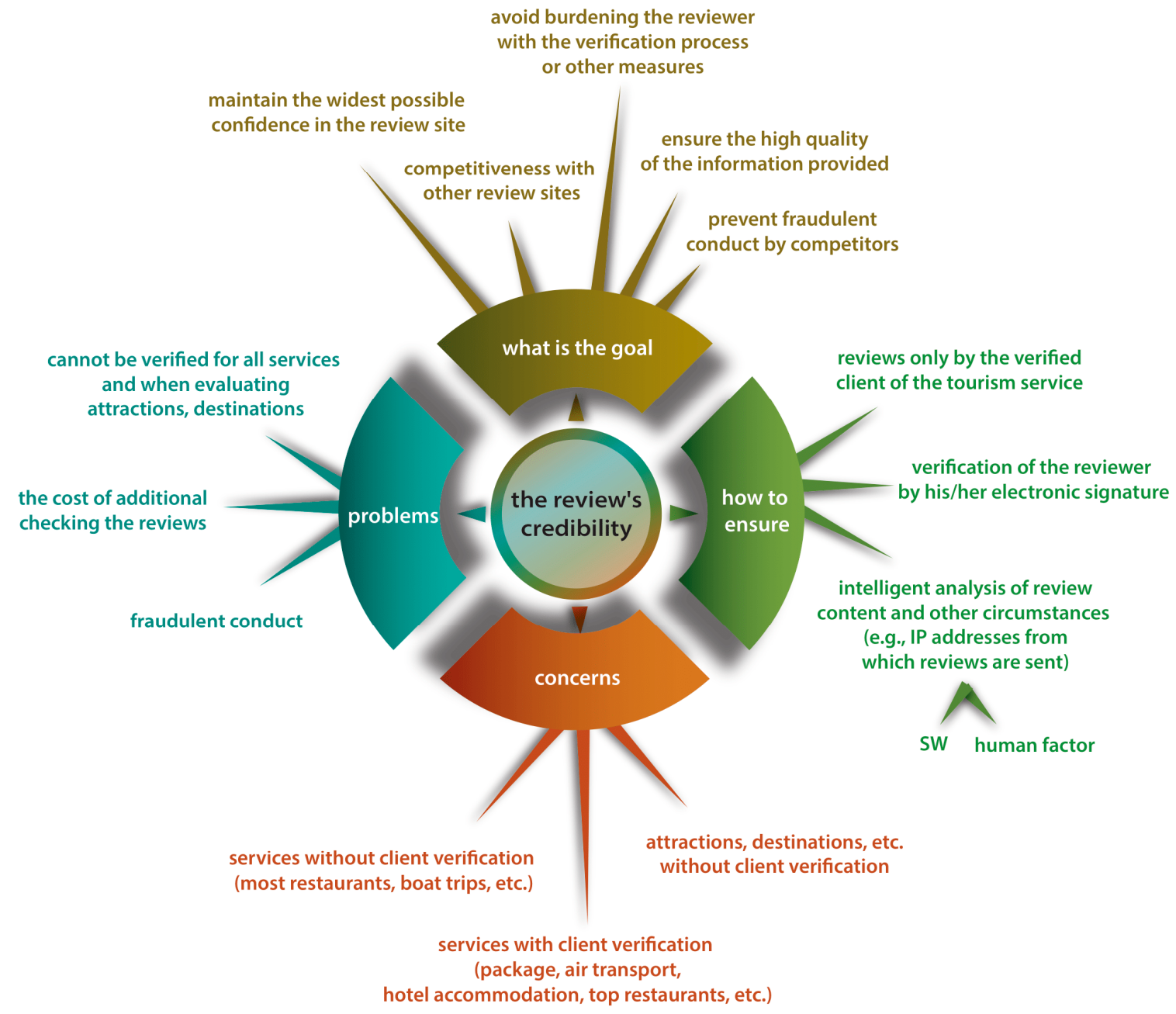

Figure 1. Factors and contexts of achieving trust in reviews on review sites. Source: Based on Filieri et al. (2015), Cardoso et al. (2018), Barbado et al. (2019), Wu et al. (2020), TripAdvisor (2020b), Zheng et al. (2021). 
Figure 1 reflects the current situation, when the verification of the reviewer may relate to some tourism services. It also indicates possible and so far, rarely used solutions. Namely, the reviewer's credibility is established by his or her electronic signature, which is attached to the review. Thus, the reviewer declares and assumes personal responsibility (including possible legal responsibility) for the content and emotional colouring of the review.

\section{Materials and Methods}

A literature review indicated the importance of trust to use UGC, especially on review sites, the growing importance of review sites and the difficulty of detecting fake reviews. Based on this, the following research questions were formulated:

Which are factors and contexts of achieving trust in reviews on review sites?

How to improve the verification process of review sites with the intention to increase trust in user-generated reviews and ratings of tourism services and destinations?

Thus, the research focused on the importance and ways of achieving trust on review sites with an emphasis on creating a conceptual model of trust for review sites. When choosing review sites for both case studies, opinions on their selection among the most important review sites were respected (Xiang et al. 2017; Borges-Tiago et al. 2021). An important selection criterion was their sophisticated approach to eliminating false and misleading reviews. As a result, the review sites TripAdvisor and Booking.com were chosen to analyse the process of processing reviews and reactions to them on review sites.

Secondary research consisting of searching for relevant data in published expert studies was based on keyword search and contextual search, focused mainly on review credibility, TripAdvisor and Booking.com, the role and perception of the influence of eWOM, UGC and CGC on tourism decision-making, and methods of detecting false reviews. Resources were searched for using the Web of Science and Scopus metainformation databases, the full-text Sciencedirect database, and the Researchgate academic social network. Some of the resources were retrieved using Google and Google Scholar. This search revealed that a significant number of relevant sources on the topic were offered on MDPI, Emerald and Taylor \& Francis Online websites. The contextual connection of related articles in the Sciencedirect, MDPI and Taylor \& Francis Online databases was used to search for relevant articles. From a large number of potentially relevant sources, the most frequently cited, most inspiring (e.g., methods of ensuring trust and authentication applied in fields other than tourism) in terms of content, and most current sources were studied in detail. The search for sources was based on a wide range of English keywords in their various combinations. These terms included, in particular, user-generated content, UGC, credibility, tourism, social media tourism, user review, review trust, fake review, spam review, tourism review site. The range of keywords used in the search was continuously supplemented with keywords used in the relevant articles. The criteria for selecting articles included the quality of the journal, the quality of the content of the article, the date of the article publication with regard to the development of the issue and the novelty of the approach, especially in methods and procedures of finding and ensuring trust in general and applied to review sites.

Literature review and secondary data collection were realized through content analysis of the published studies on that topics. Based on an extensive search of relevant sources and content analysis, factors and contexts of achieving trust in reviews on review sites has been determined.

The primary research was realised in the form of two case studies: TripAdvisor and Booking.com. The data were collected directly from the TripAdvisor and Booking.com websites by means of analysing documents and articles published there as well as reviews and responses posted there by tourism service providers. Both case studies were based on an analysis of ways of processing of user reviews, with an emphasis on ensuring validity of review verification process, clients' trust, input processes for reviews, search for false reviews, and the role of the feedback mechanism. As the analysis also included the perception of trust in reviews on both sites, the sources were supplemented with 
articles from the relevant media. The results of the analyses of both above-mentioned sites are depicted in the form of SWOT analysis of review verification processes of the process diagrams.

The proposed conceptual model and two process models of the recommended procedure for creating verified reviews resulted from the above-mentioned case studies, as well as the results of the secondary research of factors and contexts of achieving trust in reviews on review sites.

\section{Results}

\subsection{Case Study: TripAdvisor Revision Process}

Ease of use, trust in the veracity of reviews, and their usefulness for decision-making fundamentally influence the continued use of TripAdvisor (Trend 2013; Filieri et al. 2020). TripAdvisor (2020b) has several review rules (especially relevance, non-commerciality, impartiality, and easy readability) that users should follow. Adherence to these guidelines is ensured by a special software technology that runs right after submitting a review and by a team of experienced editors. This technology either allows the review to be published or blocks it and sends it to the editorial team for further assessment. Moreover, feedback from web users reporting "suspicious" reviews can be used for approved reviews (used for less than $1 \%$ of reviews) (Figure 2). Tourism service providers can either comment on approved reviews or request a recheck (the editorial team then decides whether the review remains published or is deleted, i.e., made inaccessible to web users).

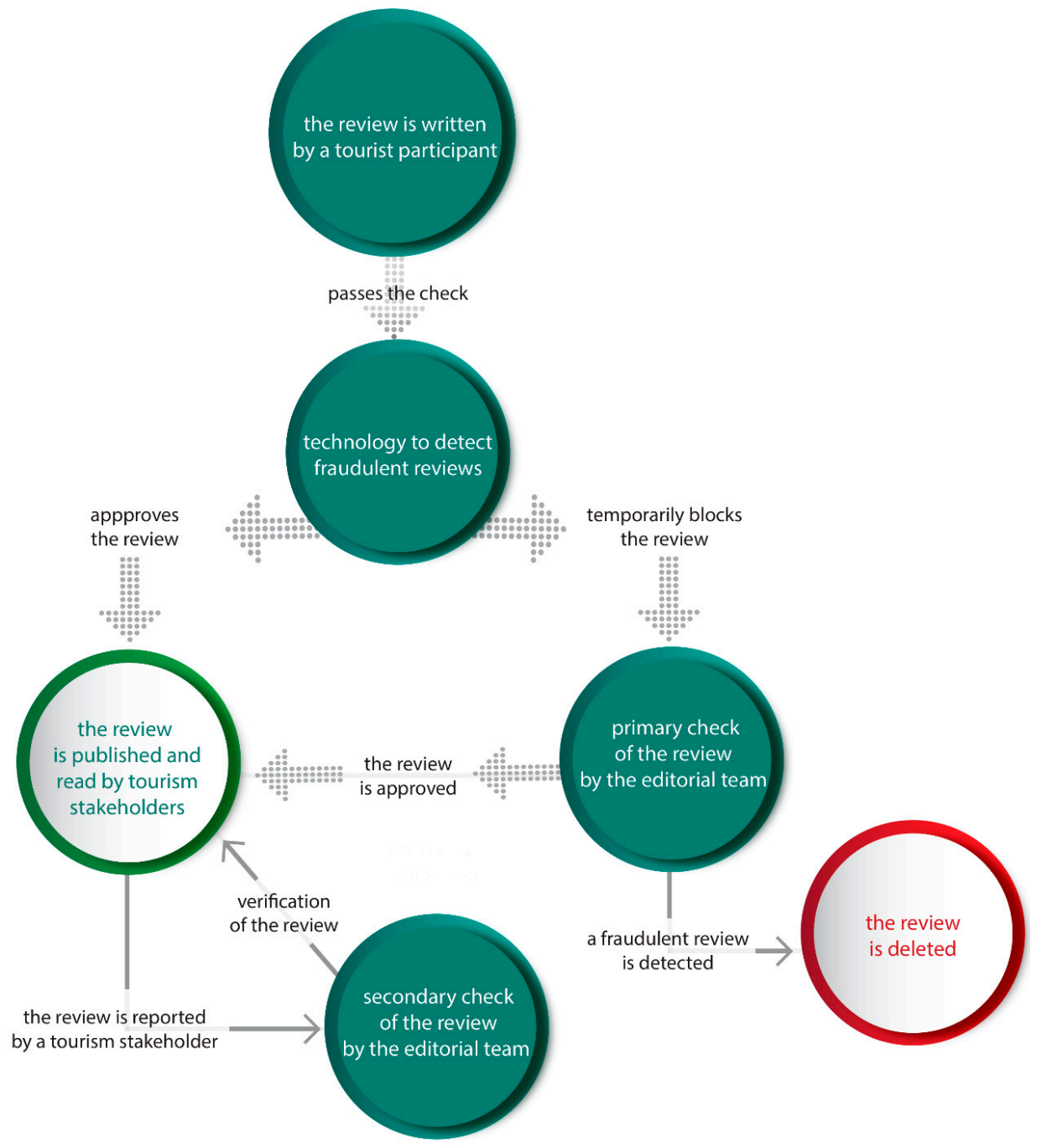

Figure 2. Review approval process on TripAdvisor. Source: TripAdvisor (2020b, 2020d). 
The process of checking the review consists of four different verification mechanisms, including the feedback from web users and tourism service providers. The effectiveness of automatic (software) check and the editors' check is further increased by learning from the experience with analysing hundreds of millions of reviews. Historical data contain patterns of behaviour and review content for both truthful and fraudulent reviewers (TripAdvisor 2018a), thus creating a knowledge base for analytical software as well as the editorial team. This learning from historical data will make it possible to capture a higher percentage of fraudulent reviews that seem genuine at first glance.

TripAdvisor aims to reduce the number of "institutionalized" false reviews by alternatively applied sanctions against tourism service providers whose fraudulent reviews have been detected. According to TripAdvisor (2020c), such providers may fall in the popularity index on the web, may lose the Travelers' Choice label (Wojcek 2016), will not be listed on the list of 10 most popular facilities and will not appear in press releases on the web. The most severe punishment is a large red sanction warning on the profile page, explaining that the reviews are suspicious (TripAdvisor 2020c).

TripAdvisor's "optimistic" claims (TripAdvisor 2018b) that more than 99\% of reviews on TripAdvisor are not false do not correspond with some independent analyses and documented cases. Several examples:

- According to The Guardian (2019), a consumer organization analysed nearly 250,000 reviews of the top 10 hotels in 10 popular tourist destinations around the world and found signs of false reviews in every seventh review.

- According to The Guardian (2018), the owner of an Italian company selling positive false reviews has been convicted of selling these reviews to hundreds of Italian restaurants.

- According to Bender (2017), perhaps the best-known example of review fraud is Oobah Butler's fictional restaurant The Shed at Dulwich, England, which became famous thanks to fake photos and reviews the top-rated restaurant in London on TripAdvisor.

\subsection{Case Study: Booking.com Revision Process}

Accommodation facilities on Booking.com are rated on a scale of one to ten (1 worst and 10 best) and by verbal ratings after individual services. The resulting average rating is a key parameter of sorting accommodation facilities according to the quality of services. The credibility of reviews is ensured in two stages (Figure 3) by authentication and authorization of the accommodated person and control of the content of the review before its publication. Authentication and authorization of the accommodated person is closely related to the reservation via Booking.com and registration of this person-only those who have booked accommodation via Booking.com and subsequently checked in will receive a unique number and are assigned the right to write a review. Booking.com is actively influencing the writing of reviews. An e-mail is sent within $48 \mathrm{~h}$ after checkout with a request to fill in a review, which can be written within three months from the date of the stay (Booking.com 2020a). By announcing that the reviews published on their website are completely reliable, Booking.com (2020a) supports the increase in the level of trust felt. It also states that only reviews that do not meet the following conditions are deleted: authenticity, clarity, suitability for a global audience, related to travel, and respect the privacy of others. This can be understood as looking for a balance between trust in reviews and freedom of expression. According to Booking.com (2020b), the owner of the reviewed facility can report an already published review via Booking.com Partner hub. The editorial team further examines the review to verify whether the reviewer has actually stayed at the facility or is attempting to blackmail it. If the latter is the case, the editorial team deletes the review. If the editorial team comes across offensive language, discrimination, threats, political and religious comments, or the disclosure of personal information, then Booking.com deletes only the text of the review and keeps the numerical score. 


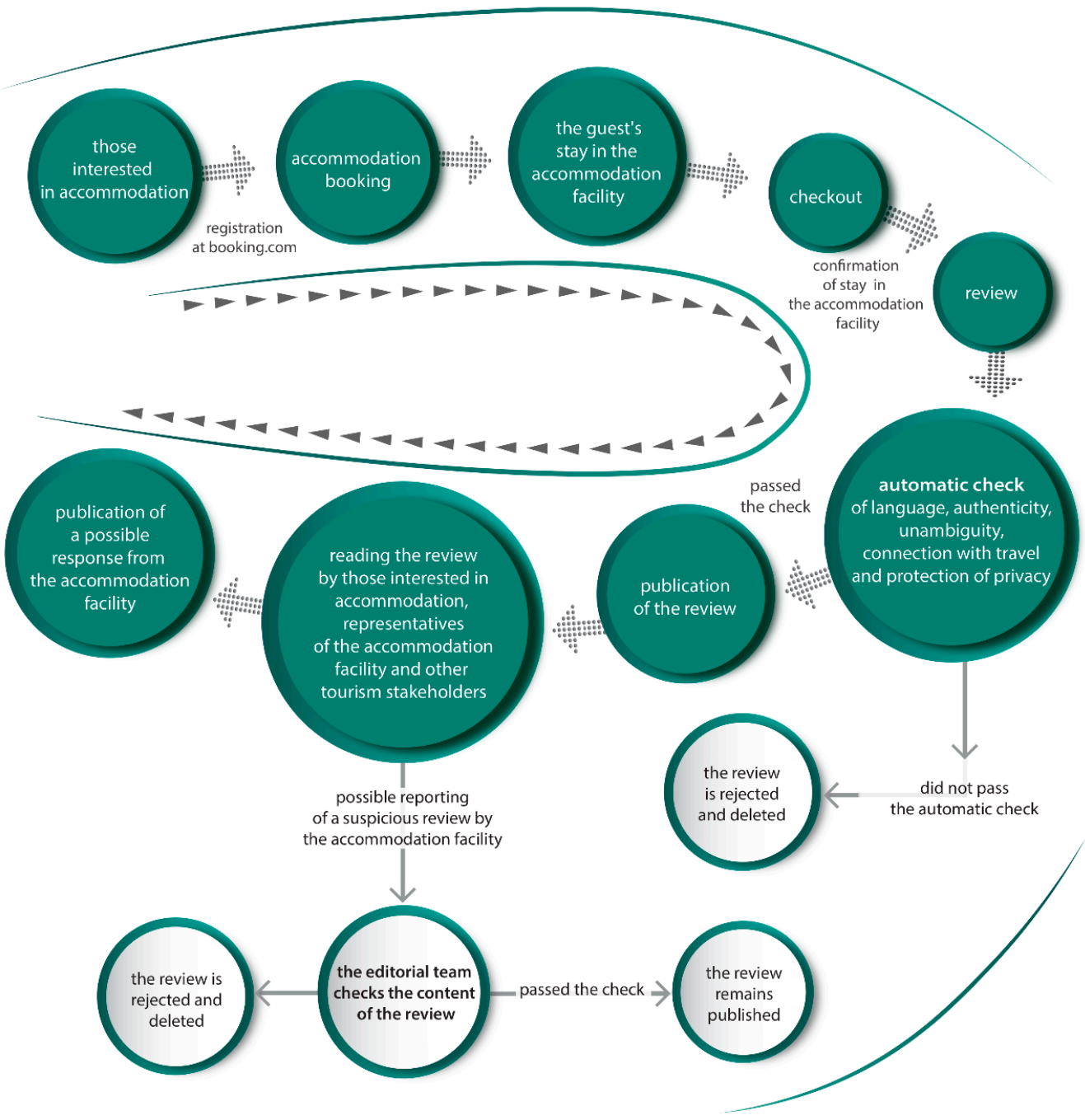

Figure 3. Booking.com review process. Source: Booking.com (2020a, 2020b).

The following Table 1 provides a summary of the case studies in Sections 4.1 and 4.2 in the form of a SWOT analysis.

Table 1. A SWOT analysis of review verification processes of TripAdvisor and Booking.com review sites. Sources: TripAdvisor (2020b, 2020d), Booking.com (2020a, 2020b).

\begin{tabular}{|c|c|c|}
\hline & TripAdvisor & Booking.com \\
\hline $\mathrm{S}$ & $\begin{array}{l}\text { - } \quad \text { two-step primary review evaluation-an automated and } \\
\text { editorial team } \\
\text { subsequent evaluation of reviews at the initiative of relevant } \\
\text { stakeholders } \\
\text { - } \quad \text { global approach } \\
\text { sharing review is easy and fast translated to } 28 \text { languages }\end{array}$ & $\begin{array}{l}\text { - } \quad \text { trustworthiness of the reviews } \\
\text { subsequent evaluation of reviews at the } \\
\text { initiative of relevant stakeholders }\end{array}$ \\
\hline W & $\begin{array}{l}\text { - } \quad \text { trustworthiness of the reviews } \\
\text { - } \quad \text { detected and described cases of publishing false reviews }\end{array}$ & $\begin{array}{l}\text { - the initial review evaluation is just only } \\
\text { automated one }\end{array}$ \\
\hline $\mathrm{O}$ & - introduction of reviewer verification procedures & - $\quad$ missing two-step primary review evaluation \\
\hline $\mathrm{T}$ & $\begin{array}{l}\text { - } \quad \text { growing number of fake reviews } \\
\text { loss of user confidence in the veracity of reviews }\end{array}$ & $\begin{array}{l}\text { - growing number of fake reviews } \\
\text { loss of user confidence in the veracity of } \\
\text { reviews }\end{array}$ \\
\hline
\end{tabular}




\subsection{Drawing Up a Trust Model on Review Sites}

The starting point for more detailed process models of trust on review sites is the following conceptual model of providing a verified review of tourism services, or verified destination assessment (Figure 4). Among the prerequisites are the verification of the destination visitor, verification of the destination visit or use of the tourism service and cooperation of the tourism service provider or destination agency (or another registered destination entity) with the review site. Feedback as a possible reaction to the published review is part of this cooperation. A newly proposed element of the review check or destination assessment is the evaluation in relation to the profile (basic characteristics) of the destination or tourism service. The conceptual model takes into account the role of end users (and other tourism stakeholders) who provide feedback for already published reviews or destination ratings and choose trustworthy reviews and ratings for themselves. According to Filieri (2016), when choosing a review and assessing the degree of its credibility, they apply content analysis and consider the style of communication and occurrence of extreme opinions.

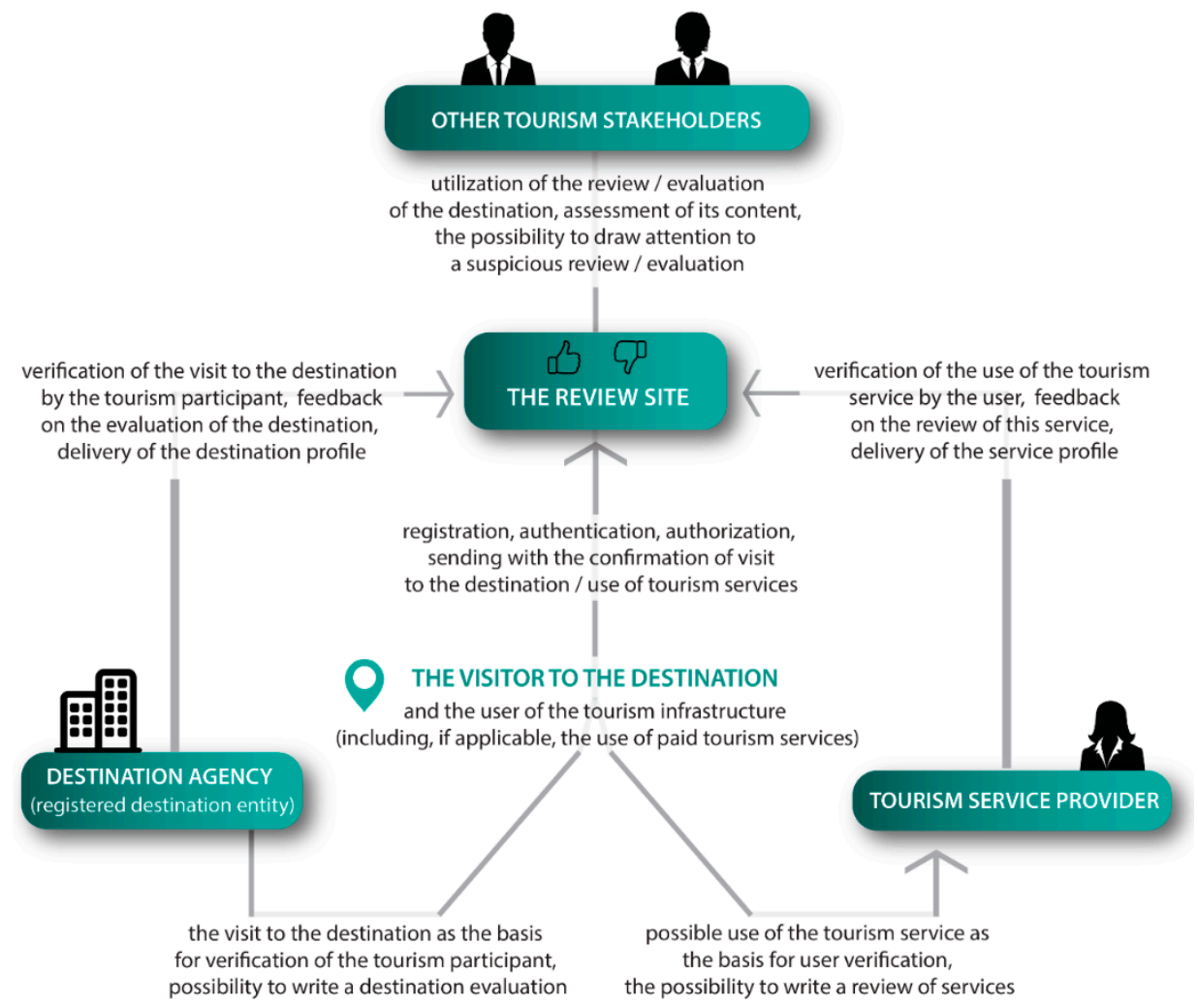

Figure 4. Conceptual model of providing a verified review of tourism services, or verified destination assessment.

The presented process model for providing a verified review of tourism services (Figure 5) includes the strengths of current procedures of TripAdvisor (multi-level check of submitted reviews) and Booking.com (authentication and authorization of the user and check of the use of booked accommodation as a precondition of sending reviews). The presented model is a system solution that includes multi-level authentication and authorization (user registration on the review site, verification of the use of tourism services by a registered tourism service provider, mediating role of the review site), as well as multilevel review check after submission and publication. The role of tourism service providers is also strengthened (sending the profile of provided services as a basis for automated and possible human control of the review). It also includes sanctions for detected false reviews as part of the prevention of false review writing. 


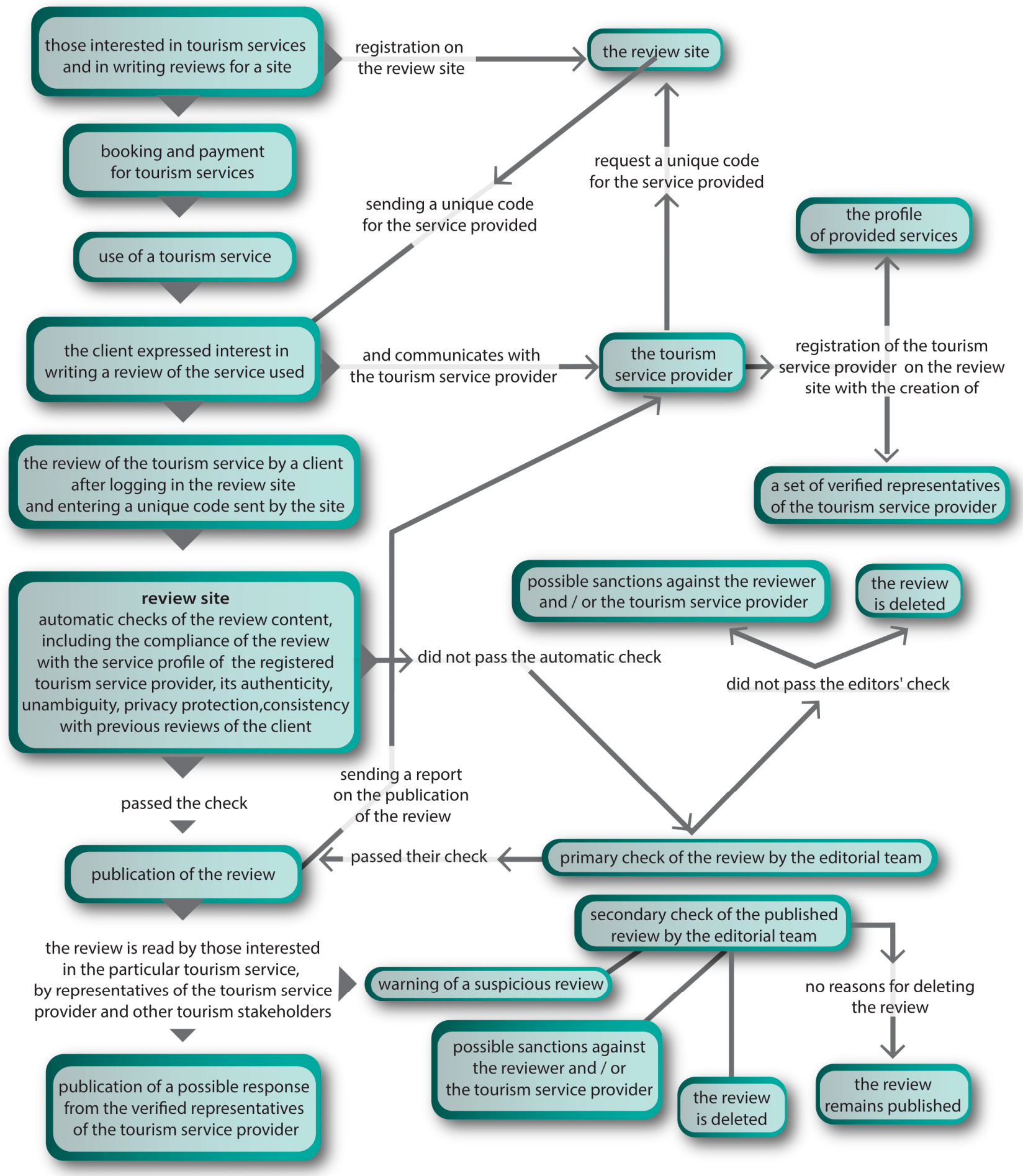

Figure 5. Process model of providing a verified review of tourism services.

The presented process model of providing verified destination assessment (Figure 6) was inspired, similarly to the process model of providing a verified review of tourism services, by the strengths of the currently used TripAdvisor and Booking.com procedures. Since tourism service providers cannot verify destination assessment, as it is in case of reviews of tourism services, there was proposed the verification of the tourist's stay in the destination by registered destination entities-destination agency, TIC, visitor's office, tourism service provider. The review site would receive warnings of suspicious destinations ratings from the destination agency. This model is another system solution 
that includes multi-level authentication and authorization (user registration on the review site, verification of his/her destination visit by a registered destination entity, mediating role of the review site), multi-level check of destination assessment after its submission and publication. Moreover, it emphasizes the role of destination agency (sending the destination profile is a basis for automated and possible human check of destination rating). It also includes sanctions for detected false destination ratings as part of the prevention of false destination assessment writing.

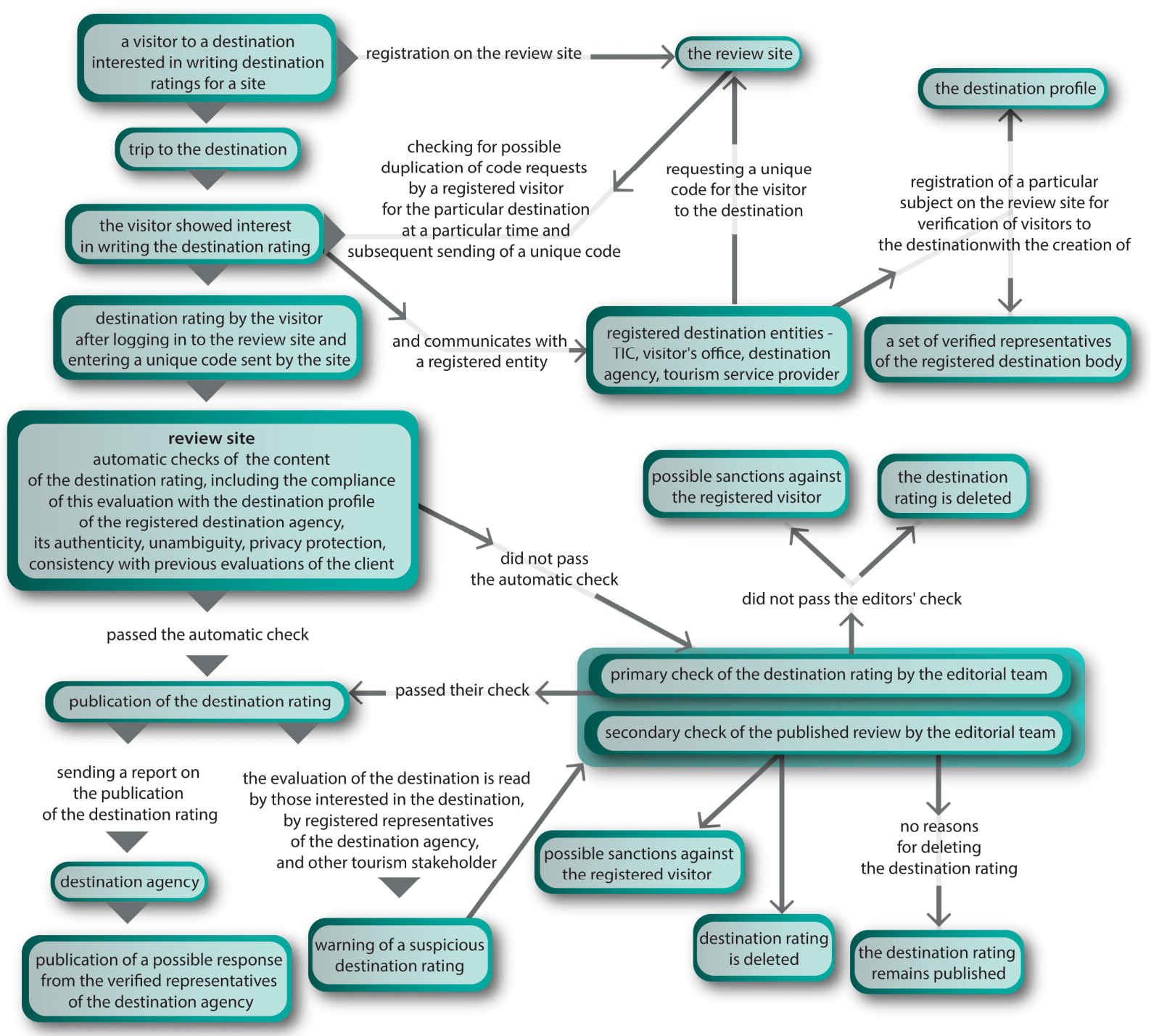

Figure 6. Process model of providing verified destination assessment.

\section{Discussion}

UGC is playing an increasingly important role in the decision-making of tourism participants in selecting the destination, its attractions, forms of sought-after experiences and tourism services offered in destinations. In the early days of Web 2.0, studies focusing on user trust in UGC, as well as comparing trust in UGC and CGC and the factors that influence that trust, were published. This trust is significantly influenced by the evaluation of the level of truth and intentional cognitive or emotional distortion of UGC content, and this is even more true of e-WOM, including reviews of tourism services and destination ratings. The existence of companies whose business is based on getting fees for removing false or misleading reviews (e.g., Removify 2020) proves the importance of this issue. 
Review sites are essentially based on a perceived level of confidence in their content. Therefore, in recent years, they intensify their efforts to prove the credibility of reviews through checks and prevention, associated in some cases with the authentication and authorization of their reviewers. At the same time, their communication aims to demonstrate efforts to eliminate false reviews, as evidenced, for example, by the first TripAdvisor report, "2019 TripAdvisor Review Transparency Report" (TripAdvisor 2020d). Both case studies show that TripAdvisor and Booking.com are currently increasing their emphasis on ensuring a higher proportion of true reviews. On the other hand, both these review sites use only some suitable preventive approaches (especially Booking.com, see Figure 2) and reactive approaches (especially TripAdvisor, see Figure 1). The disadvantage of the preventive approach of Booking.com, with its authentication and authorization of reviewers, is the fact they use it only for accommodation facilities, it is not applied for the booking of other tourism services and attractions that the website offers. The disadvantages of the reactive approach of TripAdvisor relate to the limited detection rate of false reviews, which currently does not exceed $81 \%$ for one-step checking (Plotkina et al. 2020).

The combination of preventive approach and multi-level reactive approach in the presented conceptual model and two process models significantly reduces the share of cognitively or emotionally skewed reviews and destinations ratings. What also helps is the insertion of a tourism service profile and destination profile, respectively, as a basis for automatic evaluation. The models clearly define the role of individual tourism stakeholders, propose a consistent process of authentication and authorization of the reviewer and propose sanctions for detected fraud (e.g., blacklisting). Authentication of destination reviewers is solved through registered destination entities. The presented models systematically describe the way of ensuring verified reviews, which can be a clearly established, communicated and preferred category of reviews on review sites.

\section{Conclusions}

Recently published articles have shown that the chosen topic of trust not only in review sites is highly topical. The review article by Pourfakhimi et al. (2020) confirms the importance of e-WOM in tourism. Anagnostopoulou et al. (2020) emphasize the importance of reviews for the online reputation of hotels, which according to them has an impact on hotel profitability. Yao et al. (2019) came to a similar conclusion about the significance of reviews in relation to other factors that affect the use of specific accommodation on Airbnb.

As the validity of verification process of review sites is not researched sufficiently, the present study proposes a systematic way how to reach this and thus increase the trust of review site users. The presented conceptual and process models consider various real situations of the process of writing and verifying reviews of tourism services, as well as destination ratings and systematically approaching the ways to ensure trust in them. The models also propose solutions for two areas where reviewer verification is not yet performed-services without client verification such as restaurants, boat trips, and attractions, destinations, etc. without client verification. Concerning destination ratings, the models propose a solution with authentication of the destination visitor and consistently introduce a multi-level process of verification of written reviews.

Proposed conceptual and process models can serve as inspiration for the introduction of systematic and thus more credible procedures for reviewing tourism services, attractions and destinations. This approach is very important for e-marketing, especially at the present time, when increased attention is being paid in expert assessments, scientific articles and media to fake reviews (Streitfield 2011; Smith 2013; Lipson 2016; Zhang et al. 2016; Song et al. 2017; Buccafurri et al. 2018; Cardoso et al. 2018; Barbado et al. 2019; Fedeli 2020; Wu et al. 2020; Kauffmann et al. 2020; Gadek and Guélorget 2020; Moon et al. 2020). The presented models should be verified by simulation based on real data, which demonstrates a reduction in the share of published false reviews and thus an increase in trust in review sites. A very pertinent topic of future research represents the link between trust in reviews and co-creation in tourism (Mohammadi et al. 2020). 
The future validity of the review verification process and the related trust lie in improving the quality of automatic check. An interesting method that could be used for automatic finding of false reviews is the comparison between rating scores and sentiment in verbal assessment for TripAdvisor (and thus usable for other review sites), using automated sentiment analysis methods (Valdivia et al. 2019). When using review sites as a source of information in marketing research, the systematic use of a false input filter can be expected as the first step of such research in the near future, as described, for example, by Kauffmann et al. (2020). Further research into various aspects of false communications in tourism can also be expected. For example, Fedeli (2020) proposes to examine the ethics, marketing, perception and behaviour of tourism participants, as well as safety and regulation.

Author Contributions: Conceptualization, J.Z. and T.A.; methodology J.Z. and M.P.; validation, J.Z. and T.A.; formal analysis, T.A.; investigation, T.A.; writing, J.Z. and T.A.; supervision, M.P.; project administration, J.Z; funding acquisition, J.Z. All authors have read and agreed to the published version of the manuscript.

Funding: This work was supported by the FIM UHK under the Grant of the Specific Research Project "Information and knowledge management and cognitive science in tourism".

Institutional Review Board Statement: Not applicable.

Informed Consent Statement: Not applicable.

Data Availability Statement: The data presented in this study are available on request from the corresponding author.

Acknowledgments: The authors wish to express their thanks to Zuzana Kroulíková, a FIM UHK student, who assisted with the graphical elements of this study.

Conflicts of Interest: The authors declare no conflict of interest. The funders had no role in the design of the study; in the collection, analyses, or interpretation of data; in the writing of the manuscript, or in the decision to publish the results.

\section{References}

Abubakar, Mohammed. 2016. Does eWOM influence destination trust and travel intention: a medical tourism perspective. Economic Research-Ekonomska Istraživanja 29: 598-611. [CrossRef]

Ahmad, Wasim, and Jin Sun. 2018. Modeling consumer distrust of online hotel reviews. International Journal of Hospitality Management 71: 77-90. [CrossRef]

Akhtar, Naeem, Wasim Ahmad, Umar Iqbal Siddiqi, and Muhammad Nadeem Akhtar. 2019. Predictors and outcomes of consumer deception in hotel reviews: The roles of reviewer type and attribution of service failure. Journal of Hospitality and Tourism Management 39: 65-75. [CrossRef]

Alizadeh, Abbas, and Rosmah Isa. 2014. An examination of use of social media in destination marketing. Paper presented at the First Asia-Pacific Conference on Global Business, Economics, Finance and Social Sciences (AP14Singapore Conference), Singapore, August 1-3.

Alizadeh, Abbas, and Rosmah Isa. 2015. The use of social media in destination marketing: An exploratory study. Turizam 63: 175-92.

Amaro, Suzanne, Paulo Duarte, and Carla Henriques. 2016. Travelers' use of social media: A clustering approach. Annals of Tourism Research 59: 1-15. [CrossRef]

An, Qingxiang, Yufeng Ma, Qianzhou Du, Zheng Xiang, and Weiguo Fan. 2020. Role of user-generated photos in online hotel reviews: An analytical approach. Journal of Hospitality and Tourism Management 45: 633-40. [CrossRef]

Anagnostopoulou, Seraina C., Dimitrios Buhalis, Ioanna L. Kountouri, Eleftherios G. Manousakis, and Andrianos E. Tsekrekos. 2020. The impact of online reputation on hotel profitability. International Journal of Contemporary Hospitality Management 32: 20-39. [CrossRef]

Ankomah, Paul K., and John L. Crompton. 1992. Tourism cognitive distance: A set of research propositions. Annals of Tourism Research 19: 323-42. [CrossRef]

Baka, Vasiliki. 2016. The becoming of user-generated reviews: Looking at the past to understand the future of managing reputation in the travel sector. Tourism Management 53: 148-62. [CrossRef]

Barbado, Rodrigo, Oscar Araque, and Carlos A. Iglesias. 2019. A framework for fake review detection in online consumer electronics retailers. Information Processing \& Management 56: 1234-44. [CrossRef]

Beaton, Caroline. 2018. Why You Can't Really Trust Negative Online Reviews. The New York Times. Available online: https: / / www.nytimes.com/2018/06/13/smarter-living/trust-negative-product-reviews.html (accessed on 8 December 2020). 
Bender, Andrew. 2017. TripAdvisor Gets Totally Punked When Fake Restaurant Is Ranked No. 1. Forbes. Available online: https: / / www.forbes.com/sites/andrewbender/2017/12/08/TripAdvisor-gets-totally-punked-when-fake-restaurant-isranked-no-1/\#cce2fc32c23a (accessed on 5 November 2020).

Berhanu, Kassegn, and Sahil Raj. 2020. The trustworthiness of travel and tourism information sources of social media: Perspectives of international tourists visiting Ethiopia. Heliyon 6: e03439. [CrossRef] [PubMed]

Bi, Jian-Wu Bi, Yang Liu, Zhi-Ping Fan, and Jin Zhang. 2019. Wisdom of crowds: Conducting importance-performance analysis (IPA) through online reviews. Tourism Management 70: 460-78. [CrossRef]

Bokunewicz, Jane F., and Jason Shulman. 2017. Influencer identification in Twitter networks of destination marketing organizations. Journal of Hospitality and Tourism Technology 8: 205-19. [CrossRef]

Booking.com. 2020a. What Are Guest Reviews and Who Can Write One? Available online: https://partner.booking.com/en-gb/help/ guest-reviews / what-are-guest-reviews-and-who-can-write-one (accessed on 5 November 2020).

Booking.com. 2020b. Can I Ask for a Guest Review to Be Removed? Available online: https://partner.booking.com/en-gb/help/ guest-reviews/can-i-ask-guest-review-be-removed (accessed on 16 January 2021).

Borges-Tiago, Maria Teresa, Carolina Arruda, Flavio Tiago, and Paulo Rita. 2021. Differences between TripAdvisor and Booking.com in branding co-creation. Journal of Business Research 123: 380-88. [CrossRef]

Bu, Yi, Joy Parkinson, and Park Thaichon. 2020. Digital content marketing as a catalyst for e-WOM in food tourism. Australasian Marketing Journal. in press. [CrossRef]

Buccafurri, Francesco, Gianluca Lax, Serena Nicolazzo, and Antonino Nocera. 2015. Model implementing certified reputation and its application to TripAdvisor. Paper presented at 2015 Proceedings-10th International Conference on Availability, Reliability and Security (ARES 2015), Toulouse, France, August 24-28, vol. 7299918, pp. 218-23.

Buccafurri, F., M. Fazzolari, G. Lax, and M. Petrocchi. 2018. Contrasting Fake Reviews in TripAdvisor. Paper presented at CEUR Workshop Proceedings 2161, Taranto, Italy, June 24-27.

Burgess, Stephen, Carmine Sellitto, Carmen Cox, and Jeremy Buultjens. 2009. User-generated content (UGC) in tourism: Benefits and concerns of online consumers. Paper presented at 17th European Conference on Information Systems (ECIS): Information Systems in a Globalising World: Challenges, Ethics and Practices, Verona, Italy, June 8-10; Edited by S. Newell, E. Whitley, N. Pouloudi, J. Wareham and L. Mathiassen. Verona: University of Verona, pp. 1-14. Available online: http:/ / epubs.scu.edu.au/ comm_pubs/278/ (accessed on 15 October 2020).

Burgess, Stephen, Carmine Sellitto, Carmen Cox, and Jeremy Buultjens. 2011. Trust perceptions of online travel information by different content creators: Some social and legal implications. Information Systems Frontiers 13: 221-35. [CrossRef]

Cai, Yuanfeng, and Dan Zhu. 2020. Who Can We Trust: A New Approach for Fraudulent Rater Detection in Reputation Systems. Decision Sciences 51: 80-148. [CrossRef]

Cardoso, Emerson F., Renato M. Silva, and Tiago A. Almeida. 2018. Towards automatic filtering of fake reviews. Neurocomputing 309: 106-16. [CrossRef]

Casaló, Luis V., Carlos Flavián, Miguel Guinalíu, and Yuksel Ekinci. 2015. Do online hotel rating schemes influence booking behaviors? International Journal of Hospitality Management 49: 28-36. [CrossRef]

Chan, Irene Cheng Chu, Long W. Lam, Cheris W. C. Chow, Lawrence Hoc Nang Fong, and Rob Law. 2017. The effect of online reviews on hotel booking intention: The role of reader-reviewer similarity. International Journal of Hospitality Management 66: 54-65. [CrossRef]

Chang, Yung-Chun, Chih-Hao Ku, and Chien-Hung Chen. 2020. Using deep learning and visual analytics to explore hotel reviews and responses. Tourism Management 80: 104129. [CrossRef]

Cheng, Yusi, Wei Wei, and Lu Zhang. 2020. Seeing destinations through vlogs: Implications for leveraging customer engagement behavior to increase travel intention. International Journal of Contemporary Hospitality Management 32: 3227-48. [CrossRef]

Choi, Sungwoo, Anna Mattila, Hubert Van Hoof, and Donna Quadri. 2017. The Role of Power and Incentives in Inducing Fake Reviews in the Tourism Industry. Journal of Travel Research 56: 975-87. [CrossRef]

Colicev, Anatoli, Ashish Kumar, and Peter O'Connor. 2018. Modeling the relationship between firm and user generated content and the stages of the marketing funnel. International Journal of Research in Marketing 36. [CrossRef]

Cox, Carmen, Stephen Burgess, Carmine Sellitto, and Jeremy Buultjens. 2009. The Role of User-Generated Content in Tourists' Travel Planning Behavior. Journal of Hospitality Marketing \& Management 18: 743-64. [CrossRef]

Dai, Weijia, Ginger Jin, Jungmin Lee, and Michael Luca. 2012. Optimal Aggregation of Consumer Ratings: An Application to Yelp.com. NBER Working Paper. Cambridge, MA: National Bureau of Economic Research, p. 18567.

Dickinger, Astrid. 2011. The Trustworthiness of Online Channels for Experience- and Goal-Directed Search Tasks. Journal of Travel Research 50: 378-91. [CrossRef]

Duffy, Andrew. 2015. Friends and fellow travelers: Comparative influence of review sites and friends on hotel choice. Journal of Hospitality and Tourism Technology 6: 127-44. [CrossRef]

Duffy, Andrew. 2017. Trusting me, trusting you: Evaluating three forms of trust on an information-rich consumer review website. Journal of Consumer Behavior 16: 212-20. [CrossRef]

Dwityas, Nindyta Aisyah, and Rizki Briandana. 2017. Social Media in Travel Decision Making Process. International Journal of Humanities and Social Science 7: 193-201. 
El-Said, Osman Ahmed. 2020. Impact of online reviews on hotel booking intention: The moderating role of brand image, star category, and price. Tourism Management Perspectives 33: 100604. [CrossRef]

Enter, Nina, and Eleni Michopoulou. 2013. An investigation on the Acceptance of Facebook by Travellers for Travel Planning'. e-Review of Tourism Research 4. Available online: https://agrilifecdn.tamu.edu/ertr/files/2013/03/enter2013_submission_32.pdf (accessed on 10 October 2020).

Ert, Eyal, Aliza Fleischer, and Nathan Magen. 2016. Trust and reputation in the sharing economy: The role of personal photos in Airbnb. Tourism Management 55: 62-73. [CrossRef]

Fedeli, Giancarlo. 2020. 'Fake news' meets tourism: a proposed research agenda. Annals of Tourism Research 80. [CrossRef]

Felix, Reto, Philipp A. Rauschnabel, and Chris Hinsch. 2017. Elements of strategic social media marketing: A holistic framework. Journal of Business Research 70: 118-26. [CrossRef]

Filieri, Raffaele. 2016. What makes an online consumer review trustworthy? Annals of Tourism Research 58: 46-64. [CrossRef]

Filieri, Raffaele, Salma Alguezaui, and Fraser McLeay. 2015. Why do travelers trust TripAdvisor? Antecedents of trust towards consumer-generated media and its influence on recommendation adoption and word of mouth. Tourism Management 51: 174-85. [CrossRef]

Filieri, Raffaele, Fulya Acikgoz, Valentina Ndou, and Yogesh Dwive. 2020. Is TripAdvisor still relevant? The influence of review credibility, review usefulness, and ease of use on consumers' continuance intention. International Journal of Contemporary Hospitality Management 33: 193-223. [CrossRef]

Fogel, Joshua, and Kathleen Murphy. 2018. Intentions to Use the TripAdvisor Review Website and Purchase Behavior after Reading Reviews. Human IT 14: 59-100.

Fotis, John, Dimitrios Buhalis, and Nicos Rossides. 2012. Social Media Use and Impact during the Holiday Travel Planning Process. In Information and Communication Technologies in Tourism. Edited by M. Fuchs, F. Ricci and L. Cantoni. Vienna: Springer, pp. 13-24.

Gadek, Guillaume, and Paul Guélorget. 2020. An interpretable model to measure fakeness and emotion in news. Procedia Computer Science 176: 78-87. [CrossRef]

Giglio, Simona, Francesca Bertacchini, Eleonora Bilotta, and Pietro Pantano. 2019. Using social media to identify tourism attractiveness in six Italian cities. Tourism Management 72: 306-12. [CrossRef]

Goh, Khim Yong, Cheng-Suang Heng, and Zhijie Lin. 2013. Social Media Brand Community and Consumer Behavior: Quantifying the Relative Impact of User- and Marketer-Generated Content. Information Systems Research 24: 88-107. [CrossRef]

Gossling, Stefan, C. Michael Hall, and Ann-Christin Andersson. 2018. The manager's dilemma: A conceptualization of online review manipulation strategies. Current Issues in Tourism 21: 484-503. [CrossRef]

Gössling, Stefan, Harald Zeiss, C. Michael Hall, Carlos Martin-Rios, Yael Ram, and Ivar-Petter Grøtte. 2019. A cross-country comparison of accommodation manager perspectives on online review manipulation. Current Issues in Tourism 22: 1744-63. [CrossRef]

Gretzel, Ulrike. 2018. Influencer marketing in travel and tourism. In Advances in Social Media for Travel, Tourism and Hospitality: New Perspectives, Practice and Cases. Edited by M. Sigala and U. Gretzel. New York: Routledge, pp. 147-56.

Grewal, Lauren, and Andrew T. Stephen. 2019. In Mobile We Trust: The Effects of Mobile Versus Nonmobile Reviews on Consumer Purchase Intentions. Journal of Marketing Research 56: 791-808. [CrossRef]

Guy, Ido, Avihai Mejer, Alexander Nus, and Fiana Raiber. 2017. Extracting and Ranking Travel Tips from User-Generated Reviews. Paper presented at 26th International Conference on World Wide Web, Perth, Australia, April 3-7; pp. 987-96. [CrossRef]

Ham, Juyeon, Kyungmin Lee, Taekyung Kim, and Chulmo Koo. 2019. Subjective perception patterns of online reviews: A comparison of utilitarian and hedonic values. Information Processing $\mathcal{E}$ Management 56: 1439-56. [CrossRef]

Harris, Christopher G. 2018. Decomposing TripAdvisor: Detecting Potentially Fraudulent Hotel Reviews in the Era of Big Data. Paper presented at 2018 IEEE International Conference on Big Knowledge (ICBK), Singapore, November 17-18; pp. 243-51. [CrossRef]

Hernández-Méndez, Janet, Francisco Muñoz-Leiva, and Juan Sánchez-Fernández. 2015. The influence of e-word-of-mouth on travel decision-making: Consumer profiles. Current Issues in Tourism 18: 1001-21. [CrossRef]

Hofacker, Charles F., and Daniel Belanche. 2016. Eight social media challenges for marketing managers. Spanish Journal of Marketing ESIC 20: 73-80. [CrossRef]

$\mathrm{Hu}$, Nan, Indranil Bose, Noi Sian Koh, and Ling Liu. 2012. Manipulation of online reviews: An analysis of ratings, readability, and sentiments. Decision Support Systems 52: 674-84. [CrossRef]

Huang, Ying, Hong-Yu Zhang, and Jian-Qiang Wang. 2018. A comprehensive mechanism for hotel recommendation to achieve personalized search engine. Journal of Intelligent and Fuzzy Systems 35: 3733-45. [CrossRef]

Hudson, Simon, and Karen Thal. 2013. The Impact of Social Media on the Consumer Decision Process: Implications for Tourism Marketing. Journal of Travel \& Tourism Marketing 30: 156-60. [CrossRef]

Ishida, Koji, Lisa Slevitch, and Katia Siamionava. 2016. The Effects of Traditional and Electronic Word-of-Mouth on Destination Image: A Case of Vacation Tourists Visiting Branson. Missouri. Administrative Sciences 6: 12. [CrossRef]

Jalilvand, Mohammad Reza, Sharif Shekarchizadeh Esfahani, and Neda Samiei. 2011. Electronic word-of-mouth: Challenges and opportunities. Procedia Computer Science 3: 42-46. [CrossRef]

Jaya, I Putu Gede Iwan Trisna, and Ida Bagus Teddy Prianthara. 2020. Role of Social Media Influencers in Tourism Destination Image: How Does Digital Marketing Affect Purchase Intention? Paper presented at 3rd International Conference on Vocational Higher Education (ICVHE 2018), Batam, Indonesia, August 2-4. [CrossRef] 
Jeacle, Ingrid, and Chris Carter. 2011. In TripAdvisor we trust: Rankings, calculative regimes and abstract systems. Accounting Organizations and Society 36: 293-309. [CrossRef]

Jiang, Chengzhi, Xianguo Zhang, and Aiyun Jin. 2020. Detecting Online Fake Reviews via Hierarchical Neural Networks and Multivariate Features. In Neural Information Processing (ICONIP 2020). Lecture Notes in Computer Science. Edited by H. Yang, K. Pasupa, A. C. S. Leung, J.T. Kwok, J.T. Chan and I. King. Cham: Springer, vol. 12532. [CrossRef]

Jindal, Nitin, and Bing Liu. 2008. Opinion spam and analysis. Paper presented at Conference on Web Search and Web Data Mining (WSDM'08), Palo Alto, CA, USA, February 11-12; pp. 219-30.

Kauffmann, Erick, Jesús Peral, David Gil, Antonio Ferrández, Ricardo Sellers, and Higinio Mora. 2020. A framework for big data analytics in commercial social networks: A case study on sentiment analysis and fake review detection for marketing decision-making. Industrial Marketing Management 90: 523-37. [CrossRef]

Kumar, Naveen, Deepak Venugopal, Liangfei Qiu, and Subodha Kumar. 2018. Detecting Review Manipulation on Online Platforms with Hierarchical Supervised Learning. Journal of Management Information Systems 35: 350-80. [CrossRef]

Kumar, Naveen, Deepak Venugopal, Liangfei Qiu, and Subodha Kumar. 2019. Detecting Anomalous Online Reviewers: An Unsupervised Approach Using Mixture Models. Journal of Management Information Systems 36: 1313-46. [CrossRef]

Lai, Linda S. L. 2011. A Content-Based Analysis of Travellers' Social Media Websites. Paper presented at 2011 World Congress in Computer Science, Computer Engineering, and Applied Computing, Las Vegas, NV, USA, July 18-21; pp. 547-53.

Lai, Linda S. L., and Wai Ming To. 2015. Content Analysis of Social Media: A Grounded Theory Approach. Journal of Electronic Commerce Research 16: 138-52.

Lange-Faria, W., and S. Elliot. 2012. Understanding the Role of Social Media in Destination Marketing. Tourismos: An International Multidisciplinary Journal of Tourism 7: 193-211.

Leal, Fátima, Benedita Malheiro, and Juan Carlos Burguillo. 2018. Trust and Reputation Modelling for Tourism Recommendations Supported by Crowdsourcing. In Trends and Advances in Information Systems and Technologies (WorldCIST'18). Advances in Intelligent Systems and Computing. Edited by A. Rocha, H. Adeli, L. P. Reis and S. Costanzo. Cham: Springer, vol. 745. [CrossRef]

Leal, Fátima, Benedita Malheiro, and Juan Carlos Burguillo. 2019. Incremental Hotel Recommendation with Inter-guest Trust and Similarity Post-filtering. In New Knowledge in Information Systems and Technologies (WorldCIST'19). Advances in Intelligent Systems and Computing. Edited by A. Rocha, H. Adeli, L. Reis and S. Costanzo. Cham: Springer, vol. 930. [CrossRef]

Lee, Jieun, and Ilyoo B. Hong. 2019. Consumer's Electronic Word-of-Mouth Adoption: The Trust Transfer Perspective. International Journal of Electronic Commerce 23: 595-627. [CrossRef]

Lee, Jumin, Do-Hyung Park, and Ingoo Han. 2008. The Effect of Negative Online Consumer Reviews on Product Attitude: An Information Processing View. Electronic Commerce Research and Applications 7: 341-52. [CrossRef]

Leung, Daniel, Rob Law, Hubert van Hoof, and Dimitrios Buhalis. 2013. Social Media in Tourism and Hospitality: A Literature Review. Journal of Travel \& Tourism Marketing 30: 3-22. [CrossRef]

Li, Ruohan, and Ayoung Suh. 2015. Factors Influencing Information credibility on Social Media Platforms: Evidence from Facebook Pages. Procedia Computer Science 72: 314-28. [CrossRef]

Li, Lin, Kyung Young Lee, Minwoo Lee, and Sung-Byung Yang. 2020. Unveiling the cloak of deviance: Linguistic cues for psychological processes in fake online reviews. International Journal of Hospitality Management 87: 102468. [CrossRef]

Lipson, Faye. 2016. Booking.com Security Warning after Fake Reviews-Don't Show Your Confirmation Email. MoneySavingExpert.com. Available online: https://www.moneysavingexpert.com/news/2016/07/bookingcom-security-warning-after-fake-reviews--dont-show-anyone-your-confirmation-email/ (accessed on 8 December 2020).

Litvin, W. Stephen, Ronald E. Goldsmith, and Bing Pan. 2008. Electronic word-of-mouth in hospitality and tourism management. Tourism Management 29: 458-68. [CrossRef]

López, Eduardo Parra, and Desiderio Gutiérrez Taño. 2017. The influence of reviewer identity verification on the online reputation of hotels (Book Chapter). In Advances in Social Media for Travel, Tourism and Hospitality: New Perspectives, Practice and Cases. Edited by Marianna Sigala and Ulrike Gretzel. London: Routledge, pp. 180-94.

Lou, Chen, and Shupei Yuan. 2019. Influencer Marketing: How Message Value and Credibility Affect Consumer Trust of Branded Content on Social Media. Journal of Interactive Advertising 19: 58-73. [CrossRef]

Lu, Weilin, and Svetlana Stepchenkova. 2015. User-Generated Content as a Research Mode in Tourism and Hospitality Applications: Topics, Methods, and Software. Journal of Hospitality Marketing \& Management 24: 119-54. [CrossRef]

Magno, Francesca, Fabio Cassia, and Attilio Bruni. 2018. "Please write a (great) online review for my hotel!" Guests' reactions to solicited reviews. Journal of Vacation Marketing 24: 148-58. [CrossRef]

Mahat, Nur Zarifah Dhabitah, and Mohd Hafiz Hanafiah. 2020. Help me TripAdvisor! Examining the relationship between TripAdvisor e-WOM attributes, trusts towards online reviews and travellers' behavioural intentions. Journal of Information and Organizational Sciences 44: 83-112. [CrossRef]

Maria-Irina, Ana, and Laura-Gabriela Istudor. 2019. The Role of Social Media and User-Generated-Content in Millennials' Travel Behavior. Management Dynamics in the Knowlege Economy 7: 87-104. [CrossRef]

Marine-Roig, Estela, Eva Martin-Fuentes, and Natalia Daries-Ramon. 2017. User-Generated Social Media Events in Tourism. Sustainability 9: 2250. [CrossRef]

Martinez-Torres, Maria del Rocío, and Sergio L. Toral. 2019. A machine learning approach for the identification of the deceptive reviews in the hospitality sector using unique attributes and sentiment orientation. Tourism Management 75: 393-403. [CrossRef] 
Mauri, G. Aurelio, and Roberta Minazzi. 2013. Web reviews influence on expectations and purchasing intentions of hotel potential customers. International Journal of Hospitality Management 34: 99-107. [CrossRef]

Mendes-Filho, Luiz, Annette Mills, Felix B. Tan, and Simon Milne. 2018. Empowering the traveler: An examination of the impact of user-generated content on travel planning. Journal of Travel $\mathcal{E}$ Tourism Marketing 35: 425-36. [CrossRef]

Mkono, Muchazondida. 2018. 'Troll alert!': Provocation and harassment in tourism and hospitality social media. Current Issues in Tourism 21: 791-804. [CrossRef]

Mohammadi, Fatemeh, Hamid Reza Yazdani, Mona Jami Pour, and Morteza Soltani. 2020. Co-creation in tourism: A systematic mapping study. Tourism Review. in press. [CrossRef]

Moon, Sangkil, Moon-Yong Kim, and Dawn Iacobucci. 2020. Content analysis of fake consumer reviews by survey-based text categorization. International Journal of Research in Marketing. in press. [CrossRef]

Mukherjee, Anwesha, and Manasa Nagabhushana. 2016. Role of Social Media in Tourism Marketing. International Journal of Science and Research 5: 2026-33.

Munar, Ana María, and Jens Kr. Steen Jacobsen. 2013. Trust and Involvement in Tourism Social Media and Web-Based Travel Information Sources. Scandinavian Journal of Hospitality and Tourism 13: 1-19. [CrossRef]

Nam, Kichan, Jeff Baker, Norita Ahmad, and Jahyun Goo. 2020a. Determinants of writing positive and negative electronic word-ofmouth: Empirical evidence for two types of expectation confirmation. Decision Support 129: 113168. [CrossRef]

Nam, Kichan, Jeff Baker, Norita Ahmad, and Jahyun Goo. 2020b. Dissatisfaction, Disconfirmation, and Distrust: An Empirical Examination of Value Co-Destruction through Negative Electronic Word-of-Mouth (eWOM). Information Systems Frontiers 22: 113-30. [CrossRef]

Nilashi, Mehrbakhsh, Othman Ibrahim, Elaheh Yadegaridehkordi, Sarminah Samad, Elnaz Akbari, and Azar Alizadeh. 2018. Travelers decision making using online review in social network sites: A case on TripAdvisor. Journal of Computational Science 28: 168-79. [CrossRef]

Okazaki, Shintaro, Luisa Andreu, and Sara Campo. 2017. Knowledge Sharing Among Tourists via Social Media: A Comparison between Facebook and TripAdvisor. International Journal of Tourism Research 19: 107-19. [CrossRef]

Owusu, Richard A., Crispin M. Mutshinda, Imoh Antai, Kofi Q. Dadzie, and Evelyn M. Winston. 2016. Which UGC features drive web purchase intent? A spike-and-slab Bayesian Variable Selection Approach. Internet Research 26: 22-37. [CrossRef]

Pantano, Eleonora, Constantinos-Vasilos Priporas, and Nikolaos Stylos. 2017. 'You will like it!' using open data to predict tourists' response to a tourist attraction. Tourism Management 60: 430-38. [CrossRef]

Plotkina, Daria, Andreas Munzel, and Jessie Pallud. 2020. Illusions of truth-Experimental insights into human and algorithmic detections of fake online reviews. Journal of Business Research 109: 511-23. [CrossRef]

Pourfakhimi, Shahab, Tara Duncan, and Willem J. L. Coetzee. 2020. Electronic word of mouth in tourism and hospitality consumer behaviour: State of the art. Tourism Review 75: 637-61. [CrossRef]

Prabu, Karthick. 2014. Vast Majority of TripAdvisor Users Read at Least 6-12 Reviews before Choosing Hotel. Available online: http:/ / www.tnooz.com/article/TripAdvisor-online-review-insights-phocuswright-study/ (accessed on 3 December 2020).

Rahman, Shahnoor. 2017. Tourism Destination Marketing Using Facebook as a Promotional Tool. IOSR Journal of Humanities and Social Science 22: 87-90. [CrossRef]

Rajamma, Rajasree K., Audhesh Paswan, and Nancy Spears. 2019. User-generated content (UGC) misclassification and its effects. Journal of Consumer Marketing 37: 125-38. [CrossRef]

Removify. 2020. About Removify. Available online: https://removify.com.au/content-removal/TripAdvisor/ (accessed on 17 January 2020).

Reyes-Menendez, Ana, Jose Ramon Saura, and Ferrão Filipe. 2019a. The importance of behavioral data to identify online fake reviews for tourism businesses: A systematic review. PeerJ Computer Science 5: e219. [CrossRef]

Reyes-Menendez, Ana, Jose Ramon Saura, and Juan-Gabriel Martinez-Navalon. 2019b. The Impact of e-WOM on Hotels Management Reputation: Exploring TripAdvisor Review Credibility with the ELM Model. IEEE Access 7: 68868-77. [CrossRef]

Schuckert, Markus, Xianwei Liu, and Rob Law. 2015. Hospitality and Tourism Online Reviews: Recent Trends and Future Directions. Journal of Travel $\mathcal{E}$ Tourism Marketing 32: 608-21. [CrossRef]

Schuckert, Markus, Xianwei Liu, and Rob Law. 2016. Insights into suspicious online ratings: Direct evidence from TripAdvisor Asia Pacific. Journal of Tourism Research 21: 259-72.

Shankadeep, Banerjee, Samadrita Bhattacharyya, and Indranil Bose. 2017. Whose online reviews to trust? Understanding reviewer trustworthiness and its impact on business. Decision Support Systems 96: 17-26. [CrossRef]

Sharma, Himanshu, and Anu G. Aggarwal. 2020. What factors determine reviewer credibility? An econometric approach validated through predictive modeling. Kybernetes 49: 2547-67. [CrossRef]

Smith, Oliver. 2013. TripAdvisor Fails to Spot Fake Restaurant. The Telegraph. Available online: http://www.telegraph.co.uk/travel/ travelnews /10201754/TripAdvisor-fails-to-spot-fake-restaurant.html (accessed on 3 November 2020).

Song, Wonho, Sangkon Park, and Doojin Ryu. 2017. Information Quality of Online Reviews in the Presence of Potentially Fake Reviews. Korean Economic Review, Korean Economic Association 33: 5-34.

Sotiriadis, Marios D., and Cinà van Zyl. 2013. Electronic word-of-mouth and online reviews in tourism services: The use of twitter by tourists. Electronic Commerce Research 13: 103-24. [CrossRef] 
Sparks, Beverley A., and Victoria Browning. 2011. The Impact of Online Reviews on Hotel Booking Intentions and Perception of Trust. Tourism Management 32: 1310-23. [CrossRef]

Statista. 2020. Number of User Reviews and Opinions on TripAdvisor Worldwide 2014-2019. Available online: https:/ /www.statista. com/statistics / 684862/TripAdvisor-number-of-reviews/ (accessed on 8 December 2020).

Streitfield, David. 2011. In a Race to Out-Rave, 5-Star Web Reviews Go for \$5. The New York Times. Available online: http: / / www.nytimes.com/2011/08/20/technology/finding-fake-reviews-online.html? (accessed on 3 November 2020).

Tham, Aaron, Glen Croy, and Judith Mair. 2013. Social media in destination choice: Distinctive electronic word-of-mouth dimensions. Journal of Travel E Tourism Marketing 30: 144-55. [CrossRef]

Tham, Aaron, Judith Mair, and Glen Croy. 2020. Social media influence on tourists' destination choice: Importance of context. Tourism Recreation Research 45: 161-75. [CrossRef]

The Guardian. 2018. Man Jailed in Italy for Selling Fake TripAdvisor Reviews. Available online: https:/ /www.theguardian.com/ world/2018/sep/12/man-jailed-italy-selling-fake-TripAdvisor-reviews-promo-salento (accessed on 5 November 2020).

The Guardian. 2019. TripAdvisor Is Failing to Stop Fake Hotel Reviews, Says Which? Available online: https://www.theguardian. com/travel/2019/sep/06/TripAdvisor-failing-to-stop-fake-hotel-reviews-which (accessed on 3 November 2020).

TIA. 2005. Travelers' Use of the Internet. Washington: Travel Industry Association of America.

Travel Daily News. 2012. Half of TripAdvisor Users Will Not Book a Hotel that Has No Reviews. Available online: http://www. traveldailynews.com/news/article/52077/half-of-TripAdvisor-users-will (accessed on 18 August 2014).

Trend, N. 2013. TripAdvisor and the Issue of Trust. The Telegraph. Available online: http:/ /www.telegraph.co.uk/travel/travelnews / 10399563/TripAdvisor-and-the-issue-of-trust.html (accessed on 3 December 2020).

TripAdvisor. 2018a. How Does the TripAdvisor Review Tracking System Work? Available online: https://www.TripAdvisor.com/ TripAdvisorInsights/w3690 (accessed on 5 November 2020).

TripAdvisor. 2018b. What Does TripAdvisor Do about Unfair Reviews? Available online: https://www.TripAdvisor.com/ TripAdvisorInsights/w3680 (accessed on 5 November 2020).

TripAdvisor. 2020a. About TripAdvisor. Available online: https:/ /TripAdvisor.mediaroom.com/US-about-us (accessed on 3 November 2020).

TripAdvisor. 2020b. Our Guidelines for Traveller Review. Available online: https:/ / www.TripAdvisorsupport.com/hc/en-gb/articles / 200614797-Our-guidelines-for-traveller-reviews (accessed on 3 November 2020).

TripAdvisor. 2020c. What will Happen If a Business Is Found to Have Fraudulent Reviews? Available online: https:// www.TripAdvisorsupport.com/hc/en-gb/articles/200614957-What-will-happen-if-a-business-is-found-to-have-fraudulentreviews- (accessed on 5 November 2020).

TripAdvisor. 2020d. 2019 TripAdvisor Review Transparency Report. Available online: https://www.TripAdvisor.com/ TripAdvisorInsights / w5144 (accessed on 7 October 2020).

Trusov, Michael, Randolph E. Bucklin, and Koen Pauwels. 2008. Effects of Word-of-Mouth versus Traditional Marketing: Findings from an Internet Social Networking Site. R. H. Smith School Research Paper No. RHS 06-065. College Park: R. H. Smith School, 49p. [CrossRef]

Tsao, Wen-Chin, Ming-Tsang Hsieh, Li-Wen Shih, and Tom M.Y. Lin. 2015. Compliance with eWOM: The influence of hotel reviews on booking intention from the perspective of consumer conformity. International Journal of Hospitality Management 46: 99-111. [CrossRef]

Tuttle, Brad. 2012. Why You Shouldn't Trust Positive Online Reviews-Or Negative Ones, for That Matter. Time. Available online: http: // business.time.com/2012/08/28/why-you-shouldnt-trust-positive-online-reviews-or-negative-onesfor-that-matter/ (accessed on 3 November 2020).

Valdivia, Ana, Emiliya Hrabova, Iti Chaturvedi, M. Victoria Luzón, Luigi Troiano, Erik Cambria, and Francisco Herrera. 2019. Inconsistencies on TripAdvisor reviews: A unified index between users and Sentiment Analysis Methods. Neurocomputing 353: 3-16. [CrossRef]

Verma, Sanjeev, and Neha Yadav. 2021. Past, Present, and Future of Electronic Word of Mouth (EWOM). Journal of Interactive Marketing 53: 111-28. [CrossRef]

Vincent, Cheng T. P. 2018. Amateur versus professional online reviews: Impact on tourists' intention to visit a destination. Tourism 66: 35-51.

Wang, Ping. 2015. Exploring the influence of electronic word-of-mouth on tourists' visit intention: A dual process approach. Journal of Systems and Information Technology 17: 381-95. [CrossRef]

Wojcek, Amber. 2016. How to Get Your TripAdvisor Certificate of Excellence. Travel Media Group. Available online: https://www. travelmediagroup.com/how-to-get-TripAdvisor-certificate-of-excellence/ (accessed on 5 November 2020).

Wu, Yuanyuan, Eric W. T. Ngai, Pengkun Wu, and Chong Wu. 2020. Fake online reviews: Literature review, synthesis, and directions for future research. Decision Support Systems 132. [CrossRef]

Xiang, Zheng, and Ulrike Gretzel. 2010. Role of social media in online travel information search. Tourism Management 31: 179-88. [CrossRef]

Xiang, Zheng, Qianzhou Du, Yufeng Ma, and Weiguo Fan. 2017. A comparative analysis of major online review platforms: Implications for social media analytics in hospitality and tourism. Tourism Management 58: 51-65. [CrossRef] 
Xu, Yukuan, Zili Zhang, Rob Law, and Ziqiong Zhang. 2020. Effects of online reviews and managerial responses from a review manipulation perspective. Current Issues in Tourism 23: 2207-22. [CrossRef]

Yao, Bin, Richard T. R. Qiu, Daisy X. F. Fan, Anyu Liu, and Dimitrios Buhalis. 2019. Standing out from the crowd-An exploration of signal attributes of Airbnb listings. International Journal of Contemporary Hospitality Management 31: 4520-42. [CrossRef]

Zeng, Benxiang, and Rolf Gerritsen. 2014. What do we know about social media in tourism? A review. Tourism Management Perspectives 10: 27-36. [CrossRef]

Zervas, Georgios, Davide Proserpio, and John W. Byers. 2021. A first look at online reputation on Airbnb, where every stay is above average. Marketing Letters 32: 1-16. [CrossRef]

Zhang, Dongsong, Lina Zhou, Juan Luo Kehoe, and Isil Doga Kilic. 2016. What Online Reviewer Behaviors Really Matter? Effects of Verbal and Nonverbal Behaviors on Detection of Fake Online Reviews. Journal of Management Information Systems 33: 456-81. [CrossRef]

Zheng, Tianxiang, Feiran Wu, Rob Law, Qihang Qiu, and Rong Wu. 2021. Identifying unreliable online hospitality reviews with biased user-given ratings: A deep learning forecasting approach. International Journal of Hospitality Management 92: 102658. [CrossRef] 